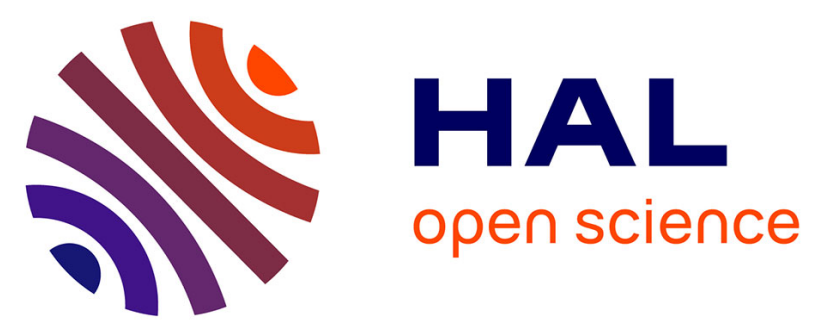

\title{
QTL analyses on genotype-specific component traits in a crop simulation model for Capsicum annuum L.
}

\author{
A. M. Wubs, E. Heuvelink, J. A. Dieleman, J. J. Magan, Alain Palloix, F. A. \\ van Eeuwijk
}

\section{To cite this version:}

A. M. Wubs, E. Heuvelink, J. A. Dieleman, J. J. Magan, Alain Palloix, et al.. QTL analyses on genotype-specific component traits in a crop simulation model for Capsicum annuum L.. 4th International Symposium on Models for Plant Growth, International Society for Horticultural Science (ISHS). INT., Nov 2012, Nanjing, China. hal-02747071

\section{HAL Id: hal-02747071 \\ https://hal.inrae.fr/hal-02747071}

Submitted on 3 Jun 2020

HAL is a multi-disciplinary open access archive for the deposit and dissemination of scientific research documents, whether they are published or not. The documents may come from teaching and research institutions in France or abroad, or from public or private research centers.
L'archive ouverte pluridisciplinaire HAL, est destinée au dépôt et à la diffusion de documents scientifiques de niveau recherche, publiés ou non, émanant des établissements d'enseignement et de recherche français ou étrangers, des laboratoires publics ou privés. 


\title{
QTL Analyses on Genotype-Specific Component Traits in a Crop Simulation Model for Capsicum annuum $\mathrm{L}$.
}

A.M. Wubs ${ }^{1}$, E. Heuvelink ${ }^{1}$, J.A. Dieleman ${ }^{2}$, J.J. Magan ${ }^{3}$, A. Palloix ${ }^{4}$ and

F.A. van Eeuwijk

${ }^{1}$ Horticultural Supply Chains, Wageningen University, P.O. Box 630, 6700 AP Wageningen, The Netherlands

${ }^{2}$ Wageningen UR Greenhouse Horticulture, P.O. Box 644, 6700 AP Wageningen, The Netherlands

${ }^{3}$ Estación Experimental de la Fundación Cajamar, Paraje Las Palmerillas 25, 04710 El Ejido, Spain

${ }^{4}$ Institut National de la Recherche Agronomique, Domaine Saint Maurice, 84143 Montfavet BP94, France

${ }^{5}$ Biometris, Wageningen University, P.O. Box 100, 6700 AC Wageningen, The Netherlands

Keywords: genotype-to-phenotype model, light use efficiency, leaf area index, total shoot biomass

\begin{abstract}
QTL for a complex trait like yield tend to be unstable across environments and show QTL by environment interaction. Direct improvement of complex traits by selecting on QTL is therefore difficult. For improvement of complex traits, crop growth models can be useful, as such models can dissect a target trait into a number of component traits. QTL for the component traits are assumed to be more stable across environments. The target trait can be reconstructed from its component traits together with environmental inputs. Instead of observed component traits, QTL fits for component traits may be used when QTL explain a reasonable proportion of the variation in the components. We applied this dissection approach to the target trait total shoot biomass for a population of 149 recombinant inbred lines from the intraspecific cross of Capsicum annuum 'Yolo Wonder' and 'Criollo de Morelos 334'. A simple LINTUL-type simulation model was used, with rate of change of leaf area index and light use efficiency as genotype specific component traits. These two component traits were determined in four phenotyping experiments (spring and autumn cultivations in the Netherlands and Spain), and subjected to QTL analysis. Seven QTL were found for both component traits. For leaf area index development rate 40 to $50 \%$ of the observed variance was explained by the QTL, while this was slightly lower for light use efficiency (23-39\%). Using the QTL fitted values of the component traits following QTL analysis, the crop simulation model explained 27$43 \%$ of the observed variation in total shoot biomass, which was higher than the variation explained by the QTL for total shoot biomass itself for most experiments. The approach of dissecting a complex trait into its component traits is therefore a promising one. Next step is to extend the model with biomass partitioning.
\end{abstract}

\section{INTRODUCTION}

Main focus in plant breeding programs is development of high yielding cultivars. This includes experiments in different contrasting environments, to evaluate performance of genotypes under different circumstances (Van Eeuwijk et al., 2005). Under these conditions, yield often shows large genotype by environment interactions, a consequence of QTL by environment interaction at the level of underlying QTL. This makes direct improvement of yield by selection on QTL for yield difficult.

It has been proposed that the combination of crop growth modelling and QTL analysis might help to overcome this problem (Hammer et al., 2006; Yin et al., 2004). In this approach, the complex target trait, for example yield, is dissected into its underlying component traits. These component traits are assumed to have less genotype-by- 
environment interaction, and therefore less QTL by environment interaction, than the target trait. With the use of a crop simulation model, the target trait can be reconstructed from the component traits. Yin et al. (2000) simulated yield of barley using QTL-fitted values for the component traits partitioning, specific leaf area and pre- and post-flowering periods. However, there was a low correlation between simulated and observed yield and biomass. Other research has focussed on other aspects of crop growth and development, like time to flowering (Yin et al., 2005; Uptmoor et al., 2008) or leaf elongation (Chenu et al., 2009). For these traits, the results of this approach were more successful.

The EU-SPICY project (www.spicyweb.eu) aimed at developing a set of tools for more efficient and faster plant breeding. Pepper was used as a model crop. One of the aims was to develop a genotype-to-phenotype model, in which yield would be reconstructed from underlying components. As a first step into modelling yield, a simple model for the production of total shoot biomass, i.e. total biomass of stem, leaves and fruit, was created, as accurate simulation of yields depends largely on accurate simulation of total biomass production. The steps involved in this process are presented and discussed in this paper.

\section{MATERIALS AND METHODS}

\section{Experiments}

In 2009, four phenotyping experiments were performed at two locations and in two seasons. The two locations were Wageningen, The Netherlands (latitude $52^{\circ} \mathrm{N}$ ), and El Ejido, Almería, Spain (latitude $36^{\circ} \mathrm{N}$ ). At each location two experiments were conducted, one in spring and one in autumn (Table 1). In these experiments, 149 genotypes of a Capsicum annuum intraspecific Recombinant Inbred Line (RIL) population $\left(6^{\text {th }}\right.$ generation) of the cross 'Yolo Wonder' $x$ 'Criollo de Morelos 334' (Barchi et al., 2007) were used, as well as both parents and the $\mathrm{F}_{1}$.

In the Netherlands, experiments were performed in four Venlo-type greenhouse compartments $(12 \times 12 \mathrm{~m})$ with glass cover. Per compartment, there were 44 plots. A plot consisted of eight plants of one genotype in an arrangement of $4 \times 2$ plants, from which the inner four plants were used for observations and final destructive harvest. 'Yolo Wonder', CM334 and the $F_{1}$ were placed in a single plot in all four compartments. Four sets of three genotypes were placed in two compartments $(1-2,2-3,3-4,4-1)$, where they appeared in two plots per compartment. Of the remaining 137 genotypes, 70 genotypes were placed in one plot in one compartment, while 67 genotypes were placed in one plot in two compartments. Plants had one main stem. Side shoots were stopped at the second internode, i.e. they had 3 leaves and 3 flowers. Plant density was app. 6.4 plants per $\mathrm{m}^{2}$. Set points for greenhouse climate were $18 / 21^{\circ} \mathrm{C}$ night/day with $16^{\circ} \mathrm{C}$ from sunset to midnight. $\mathrm{CO}_{2}$ was supplied up to app. $600 \mathrm{ppm}$ when windows opening was less than $5 \%$. At higher ventilation rates, $\mathrm{CO}_{2}$ was supplied to a level of $400 \mathrm{ppm}$. Throughout the experiment, $5 \mathrm{~min}$ data of inside temperature, humidity and $\mathrm{CO}_{2}$ concentration were measured. Radiation was measured outside at 10 minute intervals. Transmissivity of the greenhouse was $62 \%$. Additional assimilation light (SON-T) was given when outside global radiation was below $150 \mathrm{~W} \mathrm{~m}^{-2}$; lamps were switched off when global radiation was above $250 \mathrm{~W} \mathrm{~m}^{-2}$ with a maximum of $16 \mathrm{~h}$ light.

In Spain, experiments were conducted in a greenhouse of $40 \times 60 \mathrm{~m}$ with a plastic cover. The 152 genotypes were placed in 2 blocks of 192 plots each (extra plots were filled with dummy plants). Plots consisted of 10 plants in a single row, of which the inner three plants were used for measurements on plant growth and development. Plants had two main stems. In the first experiment, side shoots were stopped at the second internode and flowers were removed from the upper two nodes, i.e. side shoots had 3 leaves and 1 flower. In the second experiment, side shoots were stopped at the second internode as well but no flowers were removed, i.e. the side shoots bore 3 leaves and 3 flowers. Plant density was approx. 3 plants per $\mathrm{m}^{2}$. In the first experiment, the heating system was used when temperature was lower than $14^{\circ} \mathrm{C}$, whereas in the second experiment the heating 
system was not used. No $\mathrm{CO}_{2}$ was supplied. Climate data were registered every $5 \mathrm{~min}$ for greenhouse air temperature, humidity, $\mathrm{CO}_{2}$ concentration, and inside global radiation.

At the planting date of each experiment, 6 plants per genotype were harvested destructively. Per plant, dry weights of leaves and stems were recorded, as well as the leaf area. During the experiment, fruits were harvested (at least $50 \%$ red), and their fresh weight (all fruits) and dry weight (selection of fruits) were measured. At the end of the experiment three plants per genotype (NL) or per plot (SP) were harvested destructively, and their leaf area and dry weights of leaves, stems and fruits were measured. Not all genotypes were harvested at the same time, due to difference in plant height.

\section{Description of Simulation Model}

A simple LINTUL type simulation model (Van Ittersum et al., 2003) was used to simulate growth of shoot biomass. Total shoot biomass depended on light interception and light use efficiency (Eqn. 1).

$$
\text { Shoot }_{t}=\text { Shoot }_{t-1}+L U E * I_{t} *\left(1-e^{-k * L A I_{t-1}}\right)
$$

Shoot is the total shoot biomass per $\mathrm{m}^{2}$ at a specified time. $I_{t}$ is the radiation at day $t, k$ the extinction coefficient and $L A I$ the leaf area index at a specified time. Light use efficiency (LUE) is expressed in $\mathrm{g}$ biomass produced per MJ of intercepted radiation. $\left(1-e^{-k * L A I_{t}}\right)$ represents the fraction of intercepted radiation on day $t$ (Beer's law). The model assumes that the light use efficiency and extinction coefficient are constant over time.

Leaf area growth depended only on temperature, and increased linearly with temperature sum (Eqn. 2).

$$
L A I_{t}=L A I_{0}+L A I_{\text {rate }} * \sum_{i=0}^{i=t}\left(T_{i}-T_{b}\right)
$$

$L A I_{t}$ is the leaf area index on day $t, L A I_{0}$ is the initial leaf area index, $L A I_{\text {rate }}$ is the increase of leaf area index per degree-day. $T_{i}$ is the average $24 \mathrm{~h}$ temperature at day $i$, and $T_{b}$ is the base temperature below which no development takes place. A base temperature of $10^{\circ} \mathrm{C}$ was used. Time step of the model is one day.

\section{Derivation of Crop Parameters}

For the calculation of the rate of change of leaf area index, the increase in leaf area index between the final and initial destructive harvest was calculated. The time between these two harvests was expressed in thermal time (Eqn. 2). Rate of change of leaf area index was the ratio between the increase of leaf area index and thermal time between initial and final harvest.

Light use efficiency is the biomass produced per unit of intercepted radiation. First, the leaf area index for every day was calculated using the initial leaf area index, the average daily temperature and the rate of change of leaf area index. This resulted in daily values for the leaf area index. Using this, the daily intercepted radiation was calculated. A value of 0.7 for the extinction coefficient $k$ was used for all genotypes. Daily intercepted radiation was summed over the total growth period, resulting in the total intercepted radiation per $\mathrm{m}^{2}$. Total shoot biomass was expressed as the total shoot biomass per $\mathrm{m}^{2}$, which included the fruits which had been harvested during cultivation. Total shoot biomass production was the increase in shoot biomass between final and initial harvest. The light use efficiency is the ratio between total shoot biomass production and total intercepted radiation.

The two component traits were calculated for each of the 149 genotypes in the four experiments. Rate of change of leaf area index was calculated per plant, whereas light use efficiency was calculated per plot. Using the statistical set-up of the experiment, genotypic means were derived from the data per plant/plot using mixed models, correcting for the position of the plant/plot in the greenhouse. From this analysis, the generalized heritability (Oakey et al., 2006) for the component traits was calculated. Genetic correlations were calculated between the four experiments, as well as correlations between the two component traits within an experiment. Genotypic means, heritability 
and genetic correlations were also calculated for the target variable total shoot biomass. For this variable, harvest date was included as a covariate in the derivation of genotypic means, to correct for differences in the date of final destructive harvest between the genotypes.

\section{QTL Analysis}

The genetic map of the population consisted of 455 markers, mainly SNPs, distributed over 12 linkage groups. For the component traits and the target trait, a multienvironment QTL analysis was performed in GenStat $\left(14^{\text {th }}\right.$ version), following the methodology described by Boer et al. (2007). After the QTL analysis, estimated values for the component traits and the target trait were obtained for the four environments.

\section{Simulations}

Two type of simulations were done: 1) with the genotypic means for the component traits derived from the experiment; 2) with the values from the QTL analysis on the component traits. Simulated shoot biomass was compared to the measured genotypic total shoot biomass at the average harvest date. Explained variance by the simulations was calculated from the correlation coefficient between observed and simulated data.

\section{RESULTS}

In all four experiments, the heritability of rate of change of leaf area index was high (Table 2). The heritability for light use efficiency was lower, especially in the Netherlands. Genetic correlations between the four experiments ranged between 0.67 and 0.79 for rate of change of leaf area index, indicating that there was a low genotype-byenvironment interaction. The genetic correlations for light use efficiency ranged between 0.4 and 0.64. However, heritabilities and genetic correlations for the target trait of the study, total shoot biomass, were within the same range for the component traits (heritabilities between 0.56 and 0.87 and genetic correlations between 0.56 and 0.73 ).

For both component traits, seven QTL were found. Effect of the QTL for rate of change of leaf area index was more directed to the parent CM334, while the effect of the QTL for light use efficiency was more determined by parent 'Yolo Wonder'. Two QTL were the same (within $10 \mathrm{cM}$ ) for both component traits while another one was closely located (within $20 \mathrm{cM}$ ). In all environments the effect of the majority of the QTL was in the same direction, although the size of the effect differed. The QTL explained 40, 51, 42 and $51 \%$ of the observed variance rate of change of leaf area index in N1, N2, S1 and S2, respectively, and 37, 27, 23 and 39\% of the variance for light use efficiency in N1, N2, S1 and S2, respectively. Comparing the QTL of the component traits with the seven QTL of the target trait total shoot biomass shows that two QTL of rate of change of leaf area index were exactly the same as for total shoot biomass, while three others were located within $15 \mathrm{cM}$. For light use efficiency, one QTL was the same as for total shoot biomass and one other was located within $15 \mathrm{cM}$. There was only one QTL of total shoot biomass not found in the component traits.

Using the observed component traits to simulate total shoot biomass observed in the four experiments resulted in accurate simulation (Fig. 1A), where 93, 100, 99 and $94 \%$ of the observed variation in total shoot biomass is explained by the simulations for N1, N2, S1 and S2, respectively. Using QTL-fitted-values for the component traits in the simulations explained 40,43, 27 and $34 \%$ of the variation observed in the total shoot biomass in N1, N2, S1 and S2 (Fig. 1B). The simulation using component traits based on QTL analyses explained on average more of the variation in observed biomass than a direct QTL analysis on total shoot biomass did, where 30, 29, 34 and 37\% was explained by the QTL fit in N1, N2, S1 and S2 respectively. 


\section{DISCUSSION}

When observed component traits were replaced by their QTL-fitted values, the model explained 27 to $43 \%$ of the variation in observed total shoot biomass. In the Netherlands, this was 10 to $14 \%$ higher than for the direct QTL analysis on total shoot biomass, but in Spain it was 3 to 7\% lower. This result confirms the expectation that estimating the total shoot biomass from the QTL fits of its component traits can give better predictions than directly estimating total shoot biomass from a QTL fit.

The present crop model was very simple and contained fewer component traits than for example the models of Yin et al. (2000) and Chenu et al. (2009). Models used in these kind of exercises don't necessary have to be complex (Yin et al., 2004; Hammer et al., 2006). The right balance between detail and parsimony should among others result in stable QTL for the component traits (Hammer et al., 2006). The two component traits showed for most QTL either a consistent positive or a negative effect across environments, and could therefore be regarded as stable. However, this was also true for the target trait total shoot biomass.

This is one of the first attempts where the production of assimilates (represented here by LUE) was subjected to QTL analysis. Seven QTL were found for this component trait, but they were not very large. In order to calculate the parameter light use efficiency, the target variable total shoot biomass, is used. This component trait was therefore not independently determined from the target variable. Replacing the light use efficiency by leaf photosynthesis would avoid this, however, obtaining reliable photosynthesis curves for 149 genotypes requires numerous measurements which is not feasible in practice.

Calculation of the component traits takes into account the variation in cultivation period between the genotypes and in environmental factors like temperature and radiation, as the component traits are expressed per degree-day (rate of change of leaf area index) and per unit of radiation (light use efficiency). In contrast, when deriving the genotypic means for total shoot biomass, differences in duration of the cultivation period have to be taken into account, for which a suitable correction has to be made.

The extinction coefficient $k$, which could be seen as the third component trait, was chosen not to be genotype specific. Determination of this parameter demands light measurements across the canopy, for which the plots were not big enough, or destructive and non-destructive measurements on widely spaced plants (Park et al., 2001). The extinction coefficient depends on the type of light, leaf angle distribution and leaf characteristics (Goudriaan and Van Laar, 1994); the present value is for an average situation.

Concluding shoot biomass can be reasonably well simulated with a crop growth model using QTL based component traits, and this gave better results than directly fitting a QTL model on total shoot biomass. The next challenging step is to extend the model with a function simulating yield, either by a simple partitioning coefficient, or a more complex procedure based on sink strengths (Marcelis, 1996), and to validate the method with independent data.

\section{Literature Cited}

Barchi, L., Lefebvre, V., Lanterri, S., Nagy, I., Grandbastien, M.A. and Palloix, A. 2007. A high resolution intra-specific linkage map of pepper (Capsicum annuum L.) and the selection of reduced RILs subsets for fast mapping. Genome 50:51-60.

Boer, M.P., Wright, D., Feng, L., Podlich, D.W., Lang, L., Cooper, M. and Van Eeuwijk, F.A. 2007. A mixed-model quantitative trait loci (QTL) analysis for multipleenvironment trial data using environmental covariables for QTL-by-environment interactions, with an example in maize. Genetics 177:1801-1813.

Chenu, K., Chapman, S.C., Tardieu, F., McLean, G., Welcker, C. and Hammer, G.L. 2009. Simulating the yield impacts of organ-level quantitative trait loci associated with drought response in maize; a 'gene-to-phentype" modelling approach. Genetics 183:1507-1525.

Goudriaan, J. and Van Laar, H.H. 1994. Modelling Potential Crop Growth Processes. 
Current Issues in Production Ecology. Kluwer Academic Publishers, Dordrecht, The Netherlands.

Hammer, G., Cooper, M., Tardieu, F., Welch, S., Walsh, B., Van Eeuwijk, F., Chapman, S. and Podlich, D. 2006. Models for navigating biological complexity in breeding improved crop plants. Trends Plant Sci. 11:587-593.

Marcelis, L.M.F. 1996. Sink strength as a determinant of dry matter partitioning in the whole plant. J. Exp. Bot. 47:1281-1291.

Oakey, H., Verbyla, A., Pitchford, W., Cullis, B. and Kuchel, H. 2006. Joint modelling of additive and non-additive genetic line effects in single field trials. Theor. Appl. Genet. 113:809-819.

Park, S.E., Benjamin, L.R., Aikman, D.P. and Watkinson, A.R. 2001. Predicting the growth interactions between plants in mixed species stands using a simple mechanistic model. Ann. Bot. 87:523-536.

Uptmoor, R., Schrag, T., Stützel, H. and Esch, E. 2008. Crop model based QTL analysis across environments and QTL based estimation of time to floral induction and flowering in Brassica oleracea. Mol. Breeding 21:205-216.

Van Ittersum, M.K., Leffelaar, P.A., van Keulen, H., Kropff, M.J., Bastiaans, L. and Goudriaan, J. 2003. On approaches and application of the Wageningen crop models. Eur. J. Agron. 18:201-234.

Van Eeuwijk, F.A., Malosetti, M., Yin, X.Y., Struik, P.C. and Stam, P. 2005. Statistical models for genotype by environment data: from conventional ANOVA models to ecophysiological QTL models. Aust. J. Agri. Research 56:883-894.

Yin, X.Y., Chasalow, S.D., Dourleijn, C.J., Stam, P. and Kropff, M.J. 2000. Coupling estimated effects of QTLs for physiological traits to a crop growth model: predicting yield variation among recombinant inbred lines in barely. Heredity 85:539-549.

Yin, X.Y., Struik, P.C. and Kropff, M.J. 2004. Role of crop physiology in predicting gene-to-phenotype relationships. Trends Plant Sci. 9:426-432.

Yin, X.Y., Struik, P.C., Van Eeuwijk, F.A., Stam, P. and Tang, J.J. 2005. QTL analysis and QTL-based prediction of flowering phenology in recombinant inbred lines of barley. J. Exp. Bot. 56:967-976.

\section{$\underline{\text { Tables }}$}

Table 1. Time schedule of the experiments and average temperature and radiation of the four phenotyping experiments.

\begin{tabular}{|c|c|c|c|c|c|c|c|}
\hline & Location & Season & $\begin{array}{l}\text { Date of } \\
\text { sowing }\end{array}$ & $\begin{array}{l}\text { Date of } \\
\text { planting }\end{array}$ & $\begin{array}{c}\text { Average date } \\
\text { of final } \\
\text { harvest }\end{array}$ & $\begin{array}{l}\text { Average } \\
\text { air temp. } \\
\left({ }^{\circ} \mathrm{C}\right)\end{array}$ & $\begin{array}{c}\text { Radiation } \\
\left(\mathrm{MJ} \mathrm{m}^{-2} \mathrm{~d}^{-1}\right)^{* *}\end{array}$ \\
\hline N1* & Netherlands & Spring & 9 Dec 08 & $5 \mathrm{Feb} 09$ & 26 May 09 & 20.9 & $7.5+1.01$ \\
\hline N2 & Netherlands & Autumn & 11 Jun 09 & $15 \mathrm{Jul} 09$ & 22 Sep 09 & 22.4 & $8.5+0.69$ \\
\hline S1 & Spain & Spring & 20 Nov 08 & 14 Jan 09 & 8 Jun 09 & 19.2 & 11.0 \\
\hline S2 & Spain & Autumn & 9 Jun 09 & $16 \mathrm{Jul} 09$ & 20 Nov 09 & 22.5 & 7.1 \\
\hline
\end{tabular}

* N1 spring experiment in the Netherlands, N2 autumn experiment in the Netherlands, S1 spring experiment in Spain, S2 autumn experiment in Spain.

**Global radiation inside the greenhouse, second value in the Netherlands represent PAR from assimilation lights. 
Table 2. Heritabilities of the total shoot biomass and component traits, and correlations between component traits with an experiment.

\begin{tabular}{|c|c|c|c|c|}
\hline & \multicolumn{3}{|c|}{ Heritabilities } & \multirow{2}{*}{$\begin{array}{c}\text { Correlation } \\
\text { between } \\
\text { component traits }\end{array}$} \\
\hline & $\begin{array}{l}\text { Rate of change of } \\
\text { leaf area index }\end{array}$ & $\begin{array}{l}\text { Light use } \\
\text { efficiency }\end{array}$ & $\begin{array}{c}\text { Total shoot } \\
\text { biomass }\end{array}$ & \\
\hline N1 & 0.71 & 0.52 & 0.77 & 0.17 \\
\hline $\mathrm{N} 2$ & 0.88 & 0.66 & 0.56 & 0.32 \\
\hline S1 & 0.90 & 0.73 & 0.87 & -0.34 \\
\hline $\mathrm{S} 2$ & 0.94 & 0.75 & 0.81 & 0.00 \\
\hline
\end{tabular}

Figures
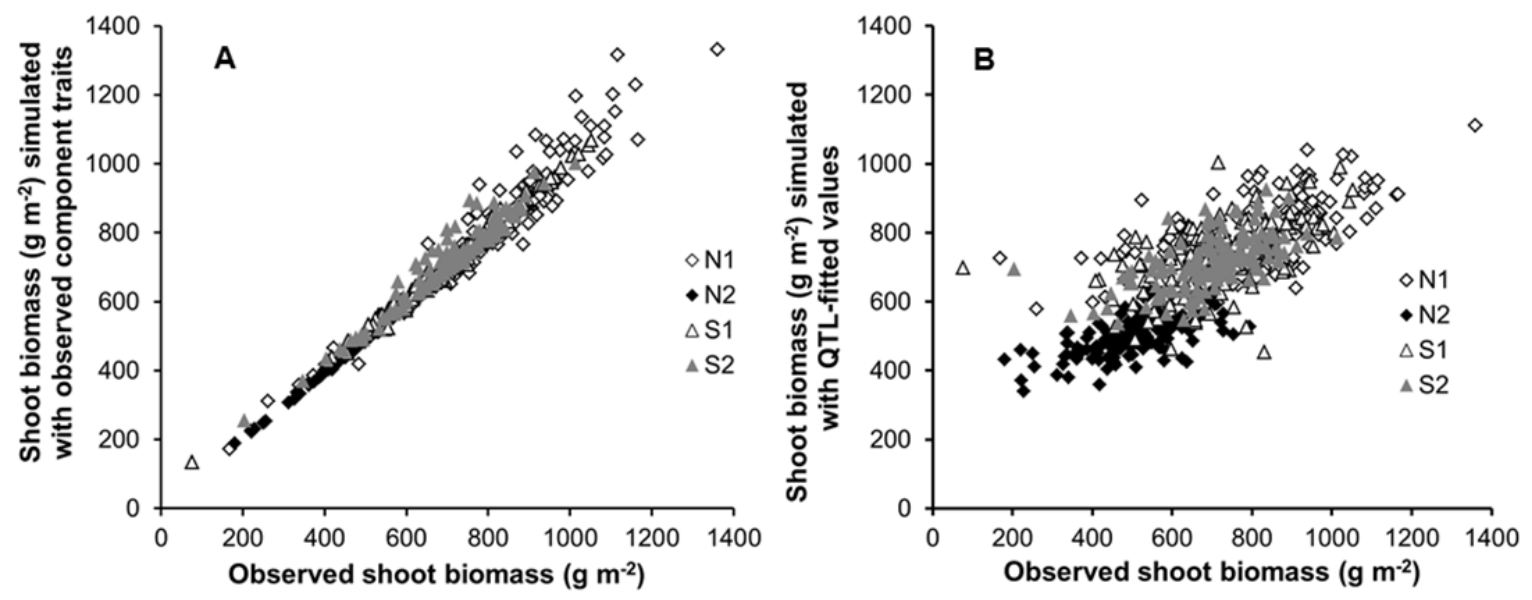

Fig. 1. Simulated total shoot biomass based on component traits as observed in the phenotyping experiments (A) and simulated total shoot biomass based on QTLfitted values for component traits (B) plotted against observed total shoot biomass. 
